\title{
Association Between Violent Video Gaming Exposure and the Attachment Styles Among Lebanese Male Adolescents
}

\author{
Marwan Akel \\ Lebanese International University \\ Jana Berro \\ Lebanese International university \\ Diana Malaeb \\ Lebanese International University \\ Iqbal Fahs \\ Lebanese International University
}

Chadia Haddad ( $\square$ Chadia_9@hotmail.com )

Psychiatric Hospital of the Cross: Hopital Psychiatrique de la Croix https://orcid.org/0000-0003-24132684

Souheil Hallit

USEK

Sahar Obeid

USEK

\section{Research article}

Keywords: video gaming, Higher age

Posted Date: January 29th, 2021

DOI: https://doi.org/10.21203/rs.3.rs-154459/v1

License: (c) (1) This work is licensed under a Creative Commons Attribution 4.0 International License. Read Full License 


\section{Abstract}

Objectives: to correlate different attachment styles with the exposure of Lebanese male adolescents to violent video games.

Methods: This study was carried out between October and December 2019 among 388 Lebanese male adolescents from five Lebanese schools.

Results: 190 participants (48.8\%, Cl: $0.43-0.53)$ were classified as having a high exposure to violent video gaming. Higher age (Beta=-1.64) and higher dismissing attachment style (Beta=-1.38) were significantly associated with less violent video gaming. Higher fearful attachment style $(B e t a=2.98)$ was significantly associated with more violent video gaming.

Conclusion: This study focuses on the association between different attachment styles and the exposure of Lebanese male adolescents to violent video games. Adolescents with more insecure attachment styles were found to be more exposed to violent video games.

\section{Introduction}

Video games, known as electronic interactive leisure activities, are mainly categorized into educational, entertainment, and violent games ${ }^{1,2}$. Violent video games are defined by those games that depict intentional attempts by individuals who can be nonhuman; cartoon characters, real persons, or anything in between to perpetrate harm on others ${ }^{3}$. It was revealed that more than $90 \%$ of Americans play video games where more than $90 \%$ of those games contain depictions of violence ${ }^{4,5}$. Exposure and popularity of video gaming are expanding and considered now as one of the largest multimedia economic activities in the world ${ }^{6}$. There are numerous extensive studies, which examined the consequences of violent video gaming. It has been documented that exposure to violent video gaming triggers the development and manifestation of aggression associated with anger and impulsivity ${ }^{7-9}$. Some reviews of research on violent video games assert that widespread exposure of young people to violent games could have major societal consequences induced through the aggressive thoughts and behaviors ${ }^{10}$. Other studies discussed that prolonged exposure to video gaming in general may have a detrimental impact on attention and focus among the users, with possibility to evolve to a clinically relevant attentional deficit with worsened scholastic performance, defective memory function, and lower intelligence ${ }^{11-14}$. In addition, playing violent video games may stimulate physiological arousal and hostility, decrease the empathy manifested through helping others, and cause a desensitizing physiological effect ${ }^{15,16}$.

Given the detrimental various consequences of violent video gaming, there are certain factors such as parental monitoring and secure attachment relationship with the parent at infancy, which might be protective against the exposure to violent video gaming ${ }^{17}$. Attachment styles were conceptualized in different ways over the years. Bartholomew and Horowitz defined four different attachment styles in regards to "the object of mental models (self or other) and the predominant feeling about that object 
(positive or negative) ${ }^{18}$." The four prototypical attachment styles derived from this model are secure, preoccupied, dismissing, and fearful. The latter three are recognized as insecure attachment styles.

Securely attached individual feel they are worthy of love and are confident to ask for support or to support others ${ }^{19}$. Preoccupied individuals are more stressed and exhibit low self-esteem, and hence, they approach their relationships while seeking approval from others ${ }^{20}$. On another hand, dismissive individuals tend to suppress their emotions and rely on themselves while prioritizing achievements over relationships. Lastly, fearful individuals view themselves as unworthy of support and exhibit high levels of distrust towards others ${ }^{21}$.

Establishment of secure attachment with primary caregiver has direct implications for negotiating new tasks, helping in actively exploring the environment, and dealing with issues of self-regulation; thus minimizing the exposure to violent video gaming ${ }^{22}$. Recent research has found significant associations among different attachment styles and problematic use of the internet including video games ${ }^{23-25}$. Attachment styles have a strong influential effect on social interactions and emotional development, which determines the risk of dependence progression, problematic use of technology, and excessive exposure to video gaming and probably the violent ones ${ }^{23,26,27}$.

Even though multiple studies were carried in order to examine the effect of violent video games on its players' aggression level, there still remains two opposing views. Some studies correlated violent video games with an increased aggression ${ }^{28}$ whereas others found minimal or no difference upon exposure to these types of games ${ }^{29}$. However, the popular and widespread public concern regarding violent games reducing empathy of those who engage in it call for further research on the topic, especially in regards to examining the factors associated with dependence of violent video gaming. Male adolescents have been shown to be the category of people that is most invested in violent video games ${ }^{30}$. Moreover, in Lebanon, there is no data regarding violent video gaming and its impact on attachment's style, in particular, among children and adolescents. Hence, this study was conducted to examine the association between violent video gaming exposure and the attachment styles among Lebanese male adolescents.

\section{Methods}

\section{Study design and procedure}

This was a cross-sectional observational study that enrolled 388 male students drawn from five Lebanese schools between October and December 2019. A list of the schools available in each Lebanese district was provided by the Ministry of Education and Higher Education; one school was chosen from each district using a simple randomization technique; the districts included the capital Beirut, Mount Lebanon, North, Beqaa, and South. A list of students was obtained from the designated school; all male students from grades $9,10,11$ and 12 (13-17 years of age) in each school were asked to participate. All students within this age group from each selected school were invited to participate. Students were 
allowed to fill the questionnaires on a voluntary basis and the survey was administered in classrooms to avoid parents' influence. Excluded were subjects who refused to complete the questionnaire. Data were stripped from any personal identifying information to protect their privacy.

\section{Minimal sample size calculation}

According to the G-power software, and based on an effect size $\mathrm{f} 2=4 \%$, an alpha error of $5 \%$, a power of $80 \%$, and taking into consideration 4 factors to be entered in the multivariable analysis, the results showed that a minimal number of 304 was needed.

\section{Data Collection and measures}

The survey questionnaire was self-report, in Arabic, and handed out on paper copy. Before use, the questionnaire was translated into Arabic (process involving two independent translations, synthesis of the two translations, back translations, review of the pre-final version and pretesting). The questionnaire included two sections. The first section collected demographic information, including participant's age and the household crowding index, which reflects the socioeconomic status of the family; the latter is calculated by dividing the number of persons living in the house by the number of rooms in the house excluding the bathrooms and kitchen. The second part was dedicated for the assessment of attachment styles and violent video games.

\section{Adolescent-Relationship Questionnaire (A-RQ)}

This self-assessment measure of attachment behavior ${ }^{31}$ consists of four short paragraphs, each describing one of the four adult attachment styles. Style A corresponds to the secure attachment, style B to the preoccupied attachment, style $C$ to the fearful attachment, and style $D$ to the dismissing attachment. Each paragraph is rated on a 7 points scale ( $1=$ strongly disagree to $7=$ strongly agree), with higher scores indicated higher attachment style (Cronbach's alpha $=0.86$ ).

\section{Video gaming}

Concerning video gaming, we asked the participant about the five most played games. The Video Game Questionnaire ${ }^{32}$ assesses the games use frequencies, the degree of violent content (blood), and the degree of violent images on a 7-point scale ( 1 = participants seldom play video games, with no violent content or image; 7 = participants often play video games with many violent contents and images). Higher scores indicate higher exposure to violent video games (Cronbach's alpha $=0.939$ ).

\section{Statistical Analysis}

SPSS software version 25 was used to conduct data analysis. The total violent gaming score was not normally distributed, therefore, non-parametric tests were used. A bivariate analysis using the Spearman correlation test served to assess the relationship between video game and the attachment styles, age, and household crowding index. A stepwise linear regression was conducted, taking the video gaming score as the dependent variable. Independent variables entered in the final model were those that showed a $p<0.2$ 
in the bivariate analysis for the elimination of confounding factors as much as possible. Significance was defined at $p<0.05$.

\section{Results}

The sociodemographic characteristics of the participants are summarized in Table 1. The results showed that the mean age of the participants was $15.83 \pm 1.93$ years ( $50 \%$ males) and the mean household crowding index of the participants was $1.39 \pm 1.59$, with $72.1 \%$ had a low monthly income. The mean video game scale score was $28.96 \pm 27.61$. In the absence of a cutoff score for this scale, we used the median as the cutoff point; the results showed that 190 (48.8\%, Cl: $0.43-0.53)$ participants were classified as having a high exposure to violent video gaming.

Table 1

Sociodemographic characteristics of the study sample

\begin{tabular}{|c|c|c|}
\hline & Frequency & Percentage \\
\hline \multicolumn{3}{|c|}{ Monthly income level in the family } \\
\hline No income & 4 & $1.2 \%$ \\
\hline$<1000 \$$ & 245 & $72.1 \%$ \\
\hline $1000-2000 \$$ & 72 & $21.2 \%$ \\
\hline \multirow[t]{2}{*}{$>2000 \$$} & 19 & $5.6 \%$ \\
\hline & Mean & SD \\
\hline Age & 15.83 & 1.93 \\
\hline Household crowding index & 1.39 & 1.59 \\
\hline
\end{tabular}

\section{Bivariate analysis}

Higher household crowding index ( $r=-0.107)$, higher secure attachment style $(r=-0.133)$ and higher dismissing attachment style $(r=-0.126)$ were significantly associated with lower use of violent video game playing. Higher fearful attachment style was significantly associated with higher use of violent video game playing $(r=0.241)$ (Table 2). 
Table 2

Bivariate analysis taking the violent video game as the dependent variable

\begin{tabular}{|c|c|c|}
\hline & Violent video game & \multirow[t]{2}{*}{ p-value } \\
\hline & Mean \pm SD & \\
\hline Age & -0.091 & 0.073 \\
\hline Household crowding index & -0.107 & 0.036 \\
\hline Secure attachment style (attachment A) & -0.133 & 0.015 \\
\hline Preoccupied attachment style (attachment B) & 0.063 & 0.257 \\
\hline Fearful attachment style (attachment C) & 0.241 & $<0.001$ \\
\hline Dismissing attachment style(attachment D) & -0.126 & 0.023 \\
\hline
\end{tabular}

\section{Multivariable analysis}

The results of the linear regression, taking the violent video game score as the dependent variable, showed that higher age (Beta=-1.64) and higher dismissing attachment style (Beta=-1.38) were significantly associated with a lower violent video game score. Higher fearful attachment style (Beta = 2.98) was significantly associated with a higher violent video game score.

Table 3

Multivariable analysis.

Linear regression taking the violent video game score as dependent variable.

\begin{tabular}{|c|c|c|c|}
\hline \multirow{2}{*}{$\begin{array}{l}\text { Unstandardized } \\
\text { Beta }\end{array}$} & \multirow{2}{*}{$\begin{array}{l}\text { Standardized } \\
\text { Beta }\end{array}$} & \multirow{2}{*}{$\begin{array}{l}\mathrm{p}- \\
\text { value }\end{array}$} & Confidence interval \\
\hline & & & $\begin{array}{l}\text { Lower } \\
\text { Bound }\end{array}$ \\
\hline
\end{tabular}

\begin{tabular}{|c|c|c|c|c|c|}
\hline Age & -1.648 & -0.100 & 0.066 & -3.408 & 0.112 \\
\hline $\begin{array}{l}\text { Fearful attachment style } \\
\text { (attachment C) }\end{array}$ & 2.981 & 0.237 & $<0.001$ & 1.630 & 4.333 \\
\hline $\begin{array}{l}\text { Dismissing attachment style } \\
\text { (attachment } D \text { ) }\end{array}$ & -1.389 & -0.123 & 0.025 & -2.603 & -0.176 \\
\hline
\end{tabular}

Variables entered in the model: Age, household crowding index, Attachment style A, Attachment style B, Attachment style C, Attachment style D.

\section{Discussion}

Although multiple research studies were carried out on the effects of excessive video game use, our study was carried out to investigate whether or not different attachment styles are associated with a higher use 
of violent video games. There is scarce literature on the association between different attachment styles and violent video games, where most studies focused on video games in general.

Our results found that 190 (48.8\%) participants were classified as being highly exposed to violent video games which is a high prevalence as found in several previous studies ${ }^{33}$. This shows that this is actually a prevalent issue amongst male adolescents in Lebanon. This is alarming and can be attributed to the severe political, social, and economic situations of the country. Teenagers might be using violent gaming for coping and escape to distract themselves from daily hassles and difficult circumstances ${ }^{34}$.

The different findings of our study suggest an association between different attachment styles and engagement in violent video games. Dismissing attachment style was associated with lower violent video game use whereas fearful attachment style was associated with higher use. Studies have shown that dismissive individuals play video games in a manner similar to their actions in their daily life, spending more time alone rather than socializing ${ }^{35}$. Hence, further studies should be done on whether their engagement in video games (even violent gaming) depends more on the genre or whether the game is an MMO (Massive Multiplayer Online gaming). These types of individuals could either be using MMOs as means to satisfy their social needs yet maintaining a barrier within that socialization, or they could be using video games that are not MMO to escape socializing altogether in their free time ${ }^{36}$.

As for individuals with a fearful attachment style, they tend to feel unworthy of support and are distrustful of others, hence they distance themselves. Their high engagement in violent video games would be their way of coping with their emotions or they could be emerging themselves in a world of their own where they escape reality and try to construct their identity through this creative platform ${ }^{37}$.

On the contrary to our findings, a recent study in the region, carried out on 1391 children and adolescent aged 9 to 15 years, had reported no differences in violent video game involvement between the three attachment patterns (secure, insecure-avoidant, and insecure-anxious) ${ }^{38}$. This can be attributed to the fact that in many current video games, violent acts are not a choice done by players but rather are part of the rules of the game. The players need to follow the rules to play effectively and achieve optimal results. However, these games have prosocial aspects such as communication with other players, sharing, and helping, which are more self-directed and autonomous; hence, they allow more of the players' personalities to be expressed in the game.

Video games have evolved into complex interactive experiences where players can freely decide on different courses of action which can result in completely different gaming experiences ${ }^{39}$. Within the same game, referred to as violent, players can exhibit violent actions such as killing and eliminating other players, and prosocial behavior such as saving the life of other players or displaying cooperation, especially when they play together in teams or groups ${ }^{40}$. Hence, creating two separate variables, one reflecting non-violent prosocial game content and the other reflecting violent content, is better to understand the association between attachment styles and exposure to violent video games. 
A higher age was correlated with a lower use of violent video games. Similar results were found in previous studies where people of lower age groups showed the most engagement with violent video games in addition to an increased time spent playing the game ${ }^{41}$. This could be due to the fact that people of lower age are still trying to determine the character that they want and online video games give them a platform to experience different characteristics and emotions ${ }^{42}$.

\section{Implications for psychiatric nursing practice}

This study highlights the importance of awareness campaigns about violent video gaming in adolescents. Gaming affects the adolescents mentally and physically. The effects are variable depending on the attachment type of the adolescents. As mental health issues are pillars in the health promotion in schools, including the effects of violence in the video games within the topics is becoming an urgency, specially that the adolescents are spending more time in front of screens, making access to violent video gaming very easy. Thus a national approach from the ministry of education would be among the best available and effective options to mandate the inclusion of emerging topics that have effects on the short and long term effects on the adolescents' well-being. It is time to consider the mental health a crucial topic among the other health components tackled in schools and media.

This project is an eye opener for all health care professionals including nursing professions dealing with mental health and wellbeing of adolescents whether be it by practice, research or education, to take into consideration the effect of violent video gaming not only on the common areas of practice like behavior, anxiety, stress and concentration among others, but also its implication on the attachment styles of the individuals. We should never forget that what the adolescents experience during their teen age will not only affect that period of life but it will definitely shape their future mental and physical health.

\section{Limitations and strengths}

The study did face several limitations as it should focus more on gender differences and the relation of gender to aggression as that might play an important role in one's exposure to violent video games. In addition, the study did not take into account the type of violent video games - whether they're MMOs or not - as that might have an impact on the relation as well. It is noteworthy to note that this study is a cross-sectional study and did not take into account different behaviors over a period of time, but rather the results were collected through self-questionnaire and the results are, thus, subject to information bias. Moreover, the scales used in the questionnaire are not validated. Finally, a residual confounding bias is also possible since not all factors associated with violent video games were taken into consideration in this study. However, this study was able to find an association between different attachment styles and exposure to violent video games, a topic that not only is newly studied in Lebanon, but is also scarcely investigated in the literature, which focuses on video games in general rather than violent ones. Not to mention, this study was quick and inexpensive to carry out while using multiple scales in regards to the aforementioned relations. 


\section{Conclusion}

This study was carried out to find an association between different attachment styles and engagement with violent video games. Our results found that individuals who exhibit fearful attachment styles are more likely to engage in violent video games, however, dismissive individuals were found to be less likely to expose themselves to violent video games. Further research should be done on stress and empathy in association with these attachment styles to investigate whether they have an impact on violent gaming exposure. In addition, studies should also focus more on the type of video games and whether they require interaction with others or not.

\section{Declarations}

\section{Ethical Approval}

The study was approved by the ethical committee at the Lebanese International University and the institutional boards of each school. A written informed consent was obtained from all students' parents.

\section{Consent for publication}

Not applicable.

\section{Availability of data and materials}

Data can be made available under reasonable request form the corresponding author.

\section{Competing interests}

The authors have nothing to disclose.

\section{Funding}

None.

\section{Authors' contribution}

SH, MA designed the study; MA, JB, DM, IF drafted the manuscript; $\mathrm{SH}, \mathrm{CH}$ carried out the analysis and interpreted the results; $\mathrm{SH}, \mathrm{SO}$ assisted in drafting and reviewing the manuscript; $\mathrm{SH}$, MA supervised the course of the article. All authors reviewed and approved the final version of the manuscript.

\section{Acknowledgments}

The authors would like to thank all the individuals who participated in this study.

\section{References}


1. Mitchell A, Savill-Smith C. The use of computer and video games for learning - a review of the literature. Learning and Skills Development Agency, Regent Arcade House 19-25 Argyll Street London W1F 7LS 2004;ISBN 1-85338-904-8: p. 2.

2. The many different. types of video games \& their subgenres. Blog \& News, posted by Vince; ID Tech,Singapore. 2018.

3. Anderson CA, Bushman BJ. Effects of violent video games on aggressive behavior, aggressive cognition, aggressive affect, physiological arousal, and prosocial behavior: a meta-analytic review of the scientific literature. Psychol Sci. 2001;12(5):353-9.

4. Rideout VJ, Foehr UG, Roberts DF. Generation M2: Media in the lives of 8- to 18-year-olds. Available at:https://kaiserfamilyfoundation.files.wordpress.com/2013/04/8010.pdf. Accessed July 29, 2013.

5. Gentile DA. The rating systems for media products. In: Calvert S, Wilson B, eds. Handbook of Children, Media, and DevelopmentOxford, England: Blackwell. 2008:527-551.

6. Peracchia S, Curcio G. Exposure to video games: effects on sleep and on post-sleep cognitive abilities. A sistematic review of experimental evidences. Sleep Sci. 2018;11(4):302-14.

7. Panee CD, Ballard ME. High Versus Low Aggressive Priming During Video-Game Training: Effects on Violent Action During Game Play, Hostility, Heart Rate, and Blood Pressure. J Appl Soc Psychol. 2002;32(12):2458-74.

8. Barlett CP, Harris RJ, Baldassaro R. Longer you play, the more hostile you feel: examination of first person shooter video games and aggression during video game play. Aggress Behav. 2007;33(6):486-97.

9. Gentile DA, Swing EL, Lim CG, Khoo A. Video Game Playing, Attention Problems, and Impulsiveness: Evidence of Bidirectional Causality. Psychol Pop Media Cult. 2012;1(1):62-70.

10. Anderson CA. An update on the effects of playing violent video games. J Adolesc. 2004;27(1):11322.

11. Christakis DA, Zimmerman FJ, DiGiuseppe DL, McCarty CA. Early television exposure and subsequent attentional problems in children. Pediatrics. 2004;113(4):708-13.

12. Swing EL, Gentile DA, Anderson CA, Walsh DA. Television and video game exposure and the development of attention problems. Pediatrics. 2010;126(2):214-21.

13. Chan PA, Rabinowitz T. A cross-sectional analysis of video games and attention deficit hyperactivity disorder symptoms in adolescents. Ann Gen Psychiatry. 2006;5:16.

14. Sharif I, Wills TA, Sargent JD. Effect of visual media use on school performance: a prospective study. J Adolesc Health. 2010;46(1):52-61.

15. Bushman BJ, Anderson CA. Comfortably numb: desensitizing effects of violent media on helping others. Psychol Sci. 2009;20(3):273-7.

16. Anderson CA, Sakamoto A, Gentile DA, et al. Longitudinal effects of violent video games on aggression in Japan and the United States. Pediatrics. 2008;122(5):e1067-72. 
17. Belsky J, Fearon RM. Infant-mother attachment security, contextual risk, and early development: a moderational analysis. Dev Psychopathol. 2002;14(2):293-310.

18. Bartholomew k. Horowitz L. Attachment Styles Among Young Adults: A Test of a Four-Category Model. J Pers Soc Psychol. 1991;61(2):226-44.

19. Ardenghi S, Rampoldi G, Bani M, Strepparava MG. Attachment styles as predictors of self-reported empathy in medical students during pre-clinical years. Patient Educ Couns. 2020;103(5):965-70.

20. Cooper ML, Shaver PR, Collins NL. Attachment styles, emotion regulation, and adjustment in adolescence. Journal of Personality Social Psychology. 1998;74(5):1380-97.

21. Tan A, Zimmermann C, Rodin G. Interpersonal processes in palliative care: an attachment perspective on the patient-clinician relationship. Palliat Med. 2005;19(2):143-50.

22. Anderson CA, Gentile DA, Buckley KE. Violent Video Game Effects on Children and Adolescents: Theory, Research, and Public Policy. New York, NY: Oxford University Press. 2007.

23. Blackwell D, Leaman C, Tramposch R, Osborne C, Liss M. Extraversion, neuroticism, attachment style and fear of missing out as predictors of social media use and addiction. Pers Individ Dif. 2017;116:69-72.

24. Assunção RS, Costa P, Tagliabue S, Matos PM. Problematic Facebook Use in Adolescents: Associations with Parental Attachment and Alienation to Peers. Journal of Child Family Studies. 2017;26:2990-8.

25. Kaye L, Fullwood C, Quinn S, Redding C. My virtual friend: A qualitative analysis of the attitudes and experiences of Smartphone users: Implications for Smartphone attachment. Comput Human Behav. 2017 May;21:75:347-55.

26. Monacis L, de Palo V, Griffiths MD, Sinatra M. Social networking addiction, attachment style, and validation of the Italian version of the Bergen Social Media Addiction Scale. J Behav Addict. 2017;6(2):178-86.

27. Goetz C. Securing home base: separation-individuation, attachment theory, and the 'virtual worlds' paradigm in video games. Psychoanal Study Child. 2017;70(1):101-16.

28. Anderson CA, Shibuya A, Ihori N, et al. Violent video game effects on aggression, empathy, and prosocial behavior in Eastern and Western countries: A meta-analytic review. Psychological bulletin. 2010;136(2):151.

29. Kühn S, Kugler DT, Schmalen K, Weichenberger M, Witt C, Gallinat J. Does playing violent video games cause aggression? A longitudinal intervention study. Molecular psychiatry. 2019;24(8):122034.

30. Gentile DA, Lynch PJ, Linder JR, Walsh DA. The effects of violent video game habits on adolescent hostility, aggressive behaviors, and school performance. Journal of adolescence. 2004;27(1):5-22.

31. Canals J, Domenech E, Carbajo G, Blade J. Prevalence of DSM-III-R and ICD-10 psychiatric disorders in a Spanish population of 18-year-olds. Acta Psychiatrica Scandinavica. 1997;96(4):287-94. 
32. Anderson CA, Dill KE. Video Games and Aggressive Thoughts, Feelings, and Behavior in the Laboratory and in Life. J Pers Soc Psychol. 2000;78,:772-90.

33. Jansz J. The emotional appeal of violent video games for adolescent males. Communication theory. 2005;15(3):219-41.

34. Schneider LA, King DL, Delfabbro PH. Maladaptive coping styles in adolescents with Internet gaming disorder symptoms. International Journal of Mental Health Addiction. 2018;16(4):905-16.

35. Mazur N. Attachment Styles and Video Game Preference and Usage. 2015.

36. Limke-McLean A. The Cost of War: Attachment and MMO Gamers' Online and Offline Relationships. Journal of Relationships Research. 2018;9.

37. Mikulincer M. Adult attachment style and individual differences in functional versus dysfunctional experiences of anger. Journal of personality social psychology. 1998;74(2):513.

38. Shoshani A, Braverman S, Meirow G. Video games and close relations: Attachment and empathy as predictors of children's and adolescents' video game social play and socio-emotional functioning. Computers in Human Behavior.114:106578.

39. Squire K. Video games and learning: Teaching and participatory culture in the digital age. Alberta Journal of Educational Research. 2013;59(1):129-32.

40. Gentile DA, Anderson CA, Yukawa S, et al. The effects of prosocial video games on prosocial behaviors: International evidence from correlational, longitudinal, and experimental studies. Personality Social Psychology Bulletin. 2009;35(6):752-63.

41. Griffiths MD, Davies MN, Chappell D. Online computer gaming: a comparison of adolescent and adult gamers. Journal of adolescence. 2004;27(1):87-96.

42. Grajewski P, Dragan M. Adverse childhood experiences, dissociation, and anxious attachment style as risk factors of gaming disorder. Addictive Behaviors Reports. 2020:100269. 